\title{
Pituitary Apoplexy Following Cardiac Surgery
}

\author{
Karim Mukhida, George Kolyvas
}

Can. J. Neurol. Sci. 2007; 34: 390-393

First described in case reports by Bailey in $1898,{ }^{1}$ Bleibtreu in $1905,{ }^{2}$ and Dingley and Lond in $1932,{ }^{3}$ and finally described as a clinical syndrome by Brougham and colleagues in 1950, ${ }^{4}$ pituitary apoplexy refers to the potentially life-threatening acute hemorrhage or infarction of a pituitary tumour. Its presentation, related to meningeal irritation and compression of the optic chiasm and parasellar structures, is variable ${ }^{5-7}$ but typically includes the sudden onset of headache, nausea, vomiting, ophthalmoplegia, altered mental status, and hormonal dysfunction. ${ }^{8}$ Pituitary apoplexy has an incidence of 0.6-16.6\% in pituitary adenomas ${ }^{6,9-12}$ and may occur spontaneously but is also associated with trauma, anticoagulation, radiation therapy, mechanical ventilation, and surgery. ${ }^{13}$ Pituitary apoplexy after cardiac surgery is an exceptionally rare perioperative complication, and all but one reported case have been managed surgically. Additionally, while spontaneous remission of endocrinopathies following pituitary apoplexy of hormonallyactive tumours is well-described, ${ }^{14-17}$ resolution of nonfunctioning tumours following apoplexy is rare. ${ }^{18,19} \mathrm{~A}$ case is presented in which no surgical management of pituitary apoplexy was required as the apoplectic event led to the spontaneous resolution of a previously undiagnosed nonfunctioning pituitary macroadenoma following cardiac surgery.

A 71 year-old man with a past medical history significant for type II diabetes mellitus, hypercholesterolemia, and unstable angina underwent five vessel coronary artery bypass grafting (CABG) with no intraoperative complications. The patient was anticoagulated with intravenous heparin (400 units $/ \mathrm{kg}$ ) and then put on the cardiopulmonary bypass machine for 122 minutes, with a cross clamp time of 78 minutes. During the bypass procedure, the hematocrit, mean arterial pressure, and blood flow decreased to as low as $18 \%, 44 \mathrm{mmHg}$, and $3.8 \mathrm{~L} /$ minute/metre ${ }^{2}$, respectively. Despite reversal with protamine intraoperatively and in the post-operative recovery room, his coagulation profiles remained elevated (normal values in parentheses): PT 19.4 (10.6 - 13.5), INR 2.0 (0.8 - 1.2), and APTT 43.7 (22.4 - 38.8). He did not receive anticoagulation post-operatively but was started on clopidogrel bisulfate. He developed a severe headache on the night immediately after the operation and in the morning complained of double vision. He was found to be drowsy with a right third nerve palsy - he demonstrated ptosis on the right with impaired ability to adduct or elevate the right eye and had a dilated and non-reactive right pupil. There was no evidence of papilledema and he had normal visual fields to confrontation.

An urgent computed tomography (CT) scan of the brain demonstrated a sellar mass with suprasellar extension. There was no hemorrhage, attenuation, or alteration within this lesion,

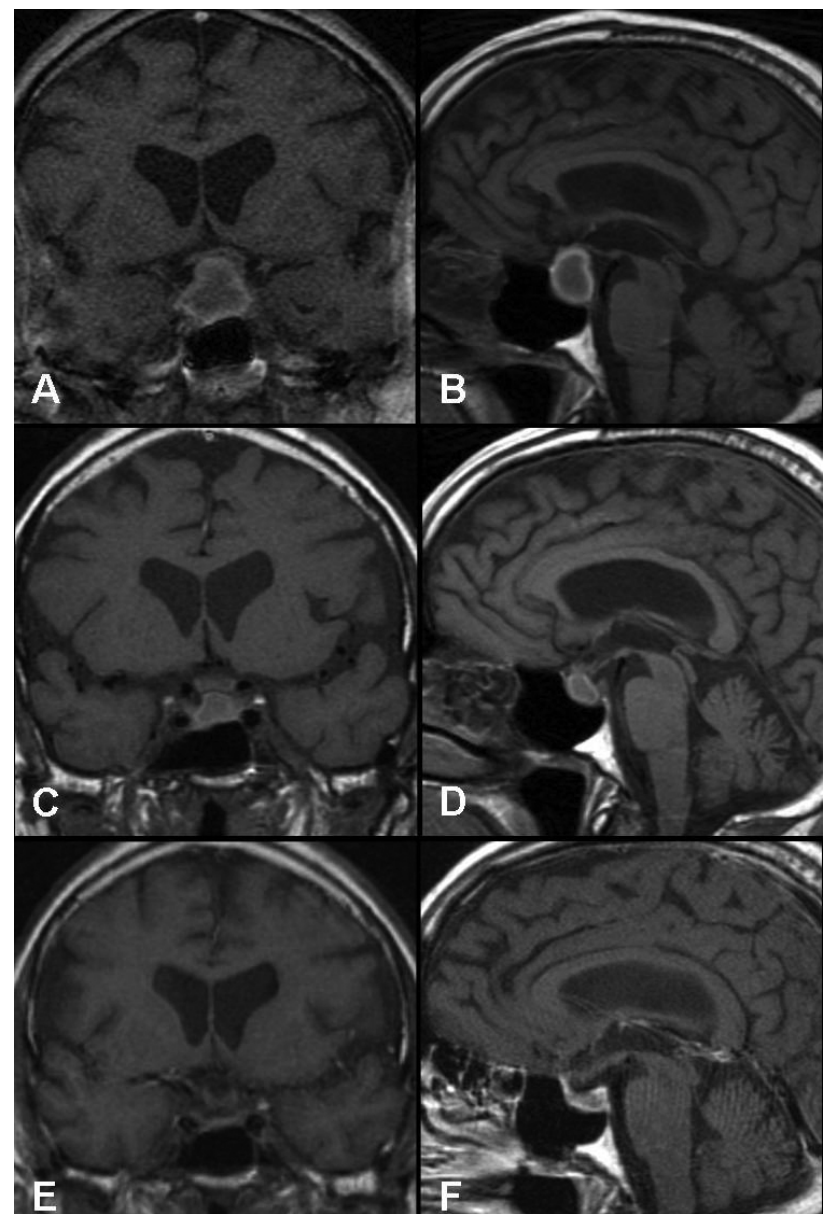

Figure: Coronal (A) and sagittal $(B)$ non-contrast magnetic resonance images performed on the day after $C A B G$ demonstrated a mass in the sella turcica with suprasellar extension and increased signal intensity peripherally indicative of hemorrhage. Imaging performed 2 months post-cardiac surgery $(C, D)$ demonstrated reduction in the size of the sellar tumour. By 7 months post-cardiac surgery, there was complete resolution of the tumour $(E, F)$.

From the Division of Neurosurgery (KM), University of Toronto, Toronto, Ontario; Division of Neurosurgery (GK), Dalhousie University and Atlantic Health Sciences Corporation, Saint John, New Brunswick, Canada.

Received February 12, 2007. AcCePTEd in final form May 5, 2007.

Reprint requests to: Karim Mukhida, Cell Restoration Laboratory, Room 12H1, Departments of Anatomy \& Neurobiology and Surgery (Neurosurgery), Dalhousie University, Sir Charles Tupper Medical Building, 5850 College Street, Halifax, Nova Scotia, B3H 1X5, Canada. 
which appeared to be a pituitary macroadenoma. Magnetic resonance imaging (MRI) (Figure A, B) demonstrated that the tumour was causing mild compression of the optic chiasm and extended to the cavernous sinuses bilaterally without encasing either carotid artery. On T2-weighted images, the lesion was isointense but peripherally showed increased signal intensity on T1-weighted images suggestive of hemorrhage.

The patient was treated with dexamethasone (4 mg intravenously q6h) because of presumed cortisol deficiency. Surgical decompression of the pituitary fossa was deferred since the patient's third nerve palsy was improving on a daily basis. Laboratory investigations subsequently revealed low testosterone but no other indications of pituitary dysfunction (normal values in parentheses): thyroid stimulating hormone (TSH) $2.27 \mathrm{mU} / \mathrm{L}$ (0.4-5.25), free T4 $9.2 \mathrm{pmol} / \mathrm{L}$ (10.3-25.7), prolactin $2 \mu \mathrm{g} / \mathrm{L}$ (3-15), testosterone $<0.7 \mathrm{pmol} / \mathrm{L}$ (7.3-26.0), FSH $1 \mathrm{U} / \mathrm{L}$ (1.4-18.1), LH <1 U/L (1.5-9.3), growth hormone (GH) $5.3 \mu \mathrm{g} / \mathrm{L}(0-3)$, cortisol $344 \mathrm{nmol} / \mathrm{L}$ (250-850). The patient was discharged from hospital on the eighth post-operative day on a tapering dose of dexamethasone since his cortisol levels were within the normal range.

Follow-up examination two months post-operatively found that the patient's third nerve palsy had resolved and his neurological examination was normal, including normal visual fields to confrontation. Imaging studies (Figure C, D) revealed significant reduction in the size of the pituitary macroadenoma with no compression of the optic chiasm. Laboratory tests again revealed low testosterone $(1.7 \mathrm{pmol} / \mathrm{L})$ and so the patient was started on Androgel. Repeat imaging seven months postoperatively revealed no evidence of the macroadenoma, and imaging two and three years following cardiac surgery confirmed its persistent absence (Figure E, F).

\section{Discussion}

As a perioperative complication of cardiac surgery, pituitary apoplexy is rare and has been reported hitherto in only 21 cases since the 1950s. ${ }^{20-35}$ A pathological study ${ }^{26}$ suggested that the incidence of pituitary apoplexy following cardiac surgery is likely more common than has been reported hitherto; the pituitaries of $15.2 \%$ of patients who died within ten days of cardiac surgery demonstrated ischemic necrosis compared to unselected autopsy cases in which only $1.4 \%$ showed similar pituitary abnormalities.

To the best of our knowledge, there is only one reported case in which pituitary apoplexy associated with cardiac surgery is documented to have led to spontaneous complete resolution of a pituitary macroadenoma. Loubani and Galiñanes ${ }^{27}$ reported the case of a 60-year-old man who developed bilateral blindness and pupillary meiosis and dissociated eye movements with alternating right and left divergence the day after elective CABG. Although magnetic resonance imaging on the first postoperative day showed only an enlarged pituitary gland with isointense signal on the T1- and T2-weighted images, repeat imaging the next day demonstrated hemorrhage into a pituitary infarction. The patient was treated with hormone-replacement therapy and gradually recovered vision over the next week in hospital. By one year post-cardiac surgery, the patient had only a minor visual field defect in the right lower temporal field and imaging demonstrated complete resolution of the pituitary adenoma. Bhattacharyya and colleagues ${ }^{22}$ have described the case of a 56-year-old man who underwent CABG with no intraoperative or immediate post-operative complications. He presented three months post-surgery with symptoms of hormone deficiency. Computed tomography demonstrated recent hemorrhage in a pituitary adenoma. He was treated medically with hormone replacement therapy, but no imaging evidence was provided of complete resolution of the tumour. Additionally, Altezani and colleagues ${ }^{21}$ have shown considerable decrease in the size, although not complete resolution, of a pituitary adenoma following apoplexy managed conservatively in a 72year-old man after redo CABG surgery.

The etiology of pituitary apoplexy associated with cardiac surgery is likely multifactorial. Pituitary adenomas are predisposed to hemorrhage and necrosis. Although typically slow-growing, adenomas can grow beyond their blood supply and can compress the hypothalamo-hypophyseal portal vessels that supply them. ${ }^{36,37}$ Vasculopathic characteristics of adenoma blood vessels also render them particularly susceptible to apoplexy; ${ }^{36,37}$ pathological examination of tumour vessels has shown abnormal sinusoids, thin-walls, hyaline changes and fibrinoid necrosis, ${ }^{28,37,38}$ all of which cause the vessels to be abnormally fragile and thus more susceptible to injury. $5,8,39,40$ Indeed, up to $25 \%$ of patients with pituitary adenomas have been found to have either imaging or surgical confirmation of hemorrhage or necrosis. ${ }^{5}$

Various aspects of cardiac surgery itself also predispose adenomas to apoplexy. During the bypass procedure, hematocrit, mean arterial pressure, and blood flow can drop to as low as $20 \%, 30 \mathrm{mmHg}$, and less than $2.2 \mathrm{~L} /$ minute/metre $^{2}$, respectively. ${ }^{24}$ Transient increases in intracranial pressure associated with positive pressure ventilation also contribute to reduced cerebral perfusion pressure. ${ }^{39}$ Hypotension predisposes adenomas to infarction and subsequent hemorrhage and was the postulated mechanism of apoplexy in other situations, such as following hemodialysis, ${ }^{41}$ large volume liposuction surgery, ${ }^{42}$ and abdominal aortic aneurysm surgery. ${ }^{43}$ Hemodilution with crystalloid during bypass can also decrease plasma oncotic pressure and result in an increase in interstitial pressure in adenomas. $^{24,28}$ Ischemia of the pituitary adenoma may result from embolization of atheroma, air bubbles, or pieces of plastic from the bypass tubing. ${ }^{44,45}$ Biousse and colleagues ${ }^{39}$ suggest that surgical stress associated with cardiac surgery may cause excessive stimulation of the pituitary due to the production of larger amounts of steroids, and Semple and colleagues ${ }^{36}$ postulate that any increase in the metabolic activity of tumours can diminish their blood supply. Lastly, anticoagulation associated with bypass surgery additionally predisposes adenomas to hemorrhage. Heparin is used for anticoagulation before the onset of bypass, but heparin reversal is incomplete in over half of patients. ${ }^{46}$ Decreased platelet counts and partial platelet dysfunction are also noted during bypass. ${ }^{24}$ The use of thrombolytic and antithrombotic medications, such as aspirin, heparin, clopidogrel, ticlopidine, and IIb-IIIa receptor antagonists, during acute coronary syndromes has been associated with pituitary apoplexy ${ }^{38,47,48}$ and, similarly, has been suggested to be important in the development of apoplexy after cardiac surgery..$^{20-35}$ It is possible that a combination of hypotension, reduced blood flow, decreased hematocrit, and 
anticoagulation during our patient's bypass procedure led to the pituitary apoplexy.

Several practical guidelines to management of pituitary apoplexy have been suggested. ${ }^{32,36,49}$ Immediate surgical treatment is suggested in patients with an impaired level of consciousness, blindness, or progressively deteriorating vision. ${ }^{32,36,49}$ Surgical treatment is also recommended if patients do not demonstrate clinical improvement within the first few days after apoplexy. ${ }^{32,36,49}$ Among the concerns that are especially relevant for surgical management of pituitary apoplexy post-cardiac surgery are those related to performance of the neurosurgical procedure while a patient may still be anticoagulated as part of their post-cardiac surgery care and the increased risk of perioperative morbidity and mortality associated with performing a surgical procedure soon after cardiac surgery. ${ }^{50-52}$ Conservative management is appropriate for patients with rapidly improving, absent, or only mild neuroopthalmological signs. ${ }^{32,36,49}$ Regardless of the type of management, patients require close monitoring and long-term follow-up to identify tumour recurrence, which has been reported to be as high as $6 \%^{8}$ and $22 \%{ }^{49}$ for patients treated surgically or only medically, respectively. Our patient continues to be seen in follow-up on an annual basis with repeat magnetic resonance imaging in order to monitor for possible tumour recurrence.

\section{REFERENCES}

1. Bailey P. Pathological report of a case of acromegaly, with especial reference to the lesions in the hypophysis cerebri and in the thyroid gland; and a case of hemorrhage into the pituitary. Philadelphia Med J. 1898; 1: 789-92.

2. Bleibtreu L. Ein fall von akromeglia (zerstorung der hypophysis durch blutung). Munch Med Wochenschr. 1905; 41: 2079-80.

3. Dingley LA, Lond MD. Sudden death due to a tumor of the pituitary gland. Lancet. 1932; 23: 183-4.

4. Brougham M, Heusner AP, Adams RD. Acute degenerative changes in adenomas of the pituitary body - with special reference to pituitary apoplexy. J Neurosurg. 1950; 7: 421-39.

5. Lubina A, Olchovsky D, Berezin M, Ram Z, Hadani M, Shimon I. Management of pituitary apoplexy: clinical experience with 40 patients. Acta Neurochir (Wien). 2005; 147: 151-7.

6. Onesti ST, Wisniewski T, Post KD. Clinical versus subclinical pituitary apoplexy: presentation, surgical management, and outcome in 21 patients. Neurosurgery. 1990; 26: 980-6.

7. Rolih CA, Ober KP. Pituitary apoplexy. Endocrinol Metab Clin North Am. 1993; 22: 291-302.

8. Randeva H, Schoebel J, Byrne J, Esiri M, Adams CB, Wass JA. Classical pituitary apoplexy: clinical features, management and outcome. Clin Endocrinol. 1999; 51: 181-8.

9. Bonicki W, Kasperlik-Zaluska A, Koszewski W, Zgliczynski W, Wislawski J. Pituitary apoplexy: endocrine, surgical and oncological emergency. Incidence, clinical course and treatment with reference to 799 cases of pituitary adenomas. Acta Neurochir (Wien). 1993; 120: 118-22.

10. Mohanty S, Tandon PN, Banerji AK, Prakash B. Haemorrhage into pituitary adenomas. J Neurol Neurosurg Psych. 1977; 40: 98791.

11. Mohr G, Hardy J. Hemorrhage, necrosis, and apoplexy in pituitary adenomas. Surg Neurol. 1982; 18: 181-9.

12. Wakai S, Fukushima T, Teramoto A, Sano K. Pituitary apoplexy: its incidence and clinical significance. J Neurosurg. 1981; 55: 18793.

13. Reid RK, Malachi EQ, Yen SSC. Pituitary apoplexy: a review. Arch Neurol. 1985: 42: 712-19.
14. Imaki T, Yamada S, Harada S, Tsuchiya M, Sano T, Demura H. Amelioration of acromegaly after pituitary infarction due to gastrointestinal hemorrhage from gastric ulcer. Endocr J. 1999; 46: $147-51$.

15. Ishibashi M, Shimada K, Abe K, Furue H, Yamaji T. Spontaneous remission in Cushing's disease. Arch Intern Med. 1993; 153: $251-5$

16. Le Nestour E, Absecassis JP, Bertagna X, Bonnin A, Luton JP. Silent necrosis of a pituitary corticotroph adenoma revealed by timely magnetic resonance imaging: a cause of spontaneous remission of Cushing's disease. Eur J Endocrinol. 1994; 130: 469-71.

17. Wichers M, Kristof RA, Springer W, Schramm J, Klingmuller D. Pituitary apoplexy with spontaneous cure of a acromegaly and its possible relation to Gd-DTPA-administration. Acta Neurochir (Wien). 1997; 139: 992-4.

18. Kachhara R, Nair S, Gupta AK. Spontaneous resolution of a nonfunctioning pituitary adenoma following an apoplexy. Neurol India. 2000; 48: 294-6.

19. Yoshino A, Katayama Y, Watanabe T, Hirota H. Vanishing pituitary mass revealed by timely magnetic resonance imaging: examples of spontaneous resolution of nonfunctioning pituitary adenoma. Acta Neurochir (Wien). 2005; 147: 253-7.

20. Absalom M, Rogers KH, Moulton RJ, Mazer CD. Pituitary apoplexy after coronary artery surgery. Anesth Analg. 1993; 76: 648-9.

21. Altezani A, Fisher C, Costa R, Ohri SK. Ptosis postcardiac surgery: a case of pituitary apoplexy. Ann Thorac Surg. 2002; 73: 3001 .

22. Bhattacharyya A, Tymms DJ, Naqvi N. Asymptomatic pituitary apoplexy after aortocoronary bypass surgery. Int $\mathrm{J}$ Clin Pract. 1999; 53: 394-5.

23. Chen Z, Murray AW, Quinlan JJ. Pituitary apoplexy presenting as unilateral third cranial nerve palsy after coronary artery bypass surgery. Anesth Analg. 2004; 98: 46-8.

24. Cooper DM, Bazaral MG, Furlan AG, Sevilla E, Ghattas MA, Sheeler LR, et al. Pituitary apoplexy: a complication of cardiac surgery. Ann Thorac Surg. 1986; 41: 547-50.

25. Glass LC. Pituitary apoplexy. N Engl J Med. 2003; 349: 21.

26. Kovacs K, Yao J. Pituitary necrosis following major heart surgery. Z Kardiol. 1975; 64: 52-7.

27. Loubani M, Galiñanes M. Pituitary gland macroadenoma: a cause of transient blindness after cardiac surgery. Ann Thorac Surg. 2001; 72: 929-31.

28. Mattke AF, Vender JR, Anstadt MP. Pituitary apoplexy presenting as addisonian crisis after coronary artery bypass grafting. Tex Heart Inst J. 2002; 29: 193-9.

29. Meek EN, Butterworth J, Kon ND, Zvara DA, Ash Jr. GE, Martin TJ. Pituitary apoplexy following mitral valve repair. Anesthesiology. 1998; 89: 1580-2.

30. Peck V, Lieberman A, Pinto R, Culliford A. Pituitary apoplexy following open heart surgery. NY State J Med. 1980; 80: 641.

31. Pliam MB, Cohen M, Cheng L, Spaenle M, Bronstein MH, Atkin TW. Pituitary adenomas complicating cardiac surgery: summary and review of 11 cases. J Card Surg. 1995; 10: 125-32.

32. Savage EB, Gugino L, Starr PA, Black PM, Cohn LH, Aranki SF. Pituitary apoplexy following cardiopulmonary bypass: considerations for a staged cardiac and neurosurgical procedure. Eur J Cardio-thoracic Surg. 1994; 8: 333-6.

33. Shapiro LM. Pituitary apoplexy following coronary artery bypass surgery. J Surg Oncol. 1990; 44: 66-8.

34. Slavin ML, Budabin M. Pituitary apoplexy associated with cardiac surgery. Am J Opthalmol. 1984; 98: 291-6.

35. Wiesmann M, Gliemroth J, Kehler U, Missler U. Pituitary apoplexy after cardiac surgery presenting as deep coma with dilated pupils. Acta Anaesthesiol Scand. 1999; 43: 236-8.

36. Semple PL, Webb MK, de Villiers JC, Laws Jr. ER. Pituitary apoplexy. Neurosurgery. 2005; 56: 65-73.

37. Cardoso ER, Peterson EW. Pituitary apoplexy: a review. Neurosurgery. 1984; 14: 363-73. 
38. Fuchs S, Beeri R, Hasin Y, Weiss T, Gostman M, Zahger D. Pituitary apoplexy as a first manifestation of pituitary adenomas following intensive thrombolytic and antithrombotic therapy. Am J Cardiol. 1998; 81; 110-1.

39. Biousse V, Newman NJ, Oyesiku NM. Precipitating factors in pituitary apoplexy. J Neurol Neurosurg Psychiatry. 2001; 71: $542-5$.

40. Piotin M, Tampieri D, Rüfenact DA, Mohr G, Garant M, Del Carpio $\mathrm{R}$, et al. The various MRI patterns of pituitary apoplexy. Eur Radiol. 1999; 9: 918-23.

41. De la Torre M, Alcázar R, Aguirre M, Ferreras I. The dialysis patient with headache and sudden hypotension: consider pituitary apoplexy. Nephrol Dial Transplant. 1998; 13: 787-8.

42. Cohen A, Kishore K, Wolansky L, Frohman L. Pituitary apoplexy occurring during large volume liposuction surgery. Neuroophthalmol. 2004; 24: 31-3.

43. Liberale G, Bruninx G, Vanderkelen B, Dubois E, Vandueren E, Verhelst G. Pituitary apoplexy after aortic abdominal surgery: a case report. Acta Chir Belg. 2006; 106: 77-80.

44. Orenstein JM, Sato N, Aaron B. Microemboli observed in deaths following cardiopulmonary bypass surgery: silicone antifoam agents and polyvinyl chloride tubing as sources of emboli. Hum Pathol. 1982; 13: 1082-90.

45. Stoney WS, Alford WC Jr, Burrus GR, Glassford DM Jr, Thomas CS Jr. Air embolism and other accidents using pump oxygenators. Ann Thorac Surg. 1980; 29: 336-40.
46. Dercksen SJ, Linssen GH. Monitoring of blood coagulation in open heart surgery: II. Use of individualized dosages of heparin and protamine controlled by activated coagulation times. Acta Anaesthesiol Belg. 1980; 31: 121-8.

47. Nagarajan DV, Bird D, Papouchado M. Pituitary apoplexy following anticoagulation for acute coronary syndrome. Heart. 2003; 89: 10 .

48. Willamowicz AS, Houlden RL. Pituitary apoplexy after anticoagulation for unstable angina. Endocr Pract. 1999; 5: 2736.

49. Sibal L, Ball SG, Connolly V, James RA, Kane P, Kelly WF, et al. Pituitary apoplexy: a review of clinical presentation, management and outcome in 45 cases. Pituitary. 2004; 7: $157-63$.

50. Glantz L, Ezri T, Cohen Y, Konichezky S, Caspi A, Geva D, et al. Perioperative myocardial ischemia in patients undergoing sternectomy shortly after coronary artery bypass grafting. Anesth Analg. 2003; 96: 1566-71.

51. Hassan SA, Hlatzky MA, Boothroyd DB, Winston C, Mark DB, Brooks MM, et al. Outcomes of noncardiac surgery after coronary bypass surgery or coronary angioplasty in the Bypass Angioplasty Revascularization Investigation (BARI). Am J Med. 2001;110: 260-6.

52. Kaluza GL, Joseph L, Lee JR, Raizner ME, Raizner AE. Catastrophic outcomes of noncardiac surgery soon after coronary stenting. J Am Coll Cardiol. 2000; 35: 1288-94. 